\title{
SEASAT RANGE MEASUREMENTS VERIFIED ON A 3-D ICE SHEET
}

\author{
by
}

\author{
N.S. Gundestrup
}

(Geophysical Institute, Glaciological Department, Haraldsgade 6, DK-2200 Copenhagen N, Denmark)

and

\author{
R.A. Bindschadler and H.J. Zwally
}

(Goddard Laboratory for Atmospheric Sciences, NASA/Goddard Space Flight Center, Greenbelt, Maryland 20771, U.S.A.)

\section{ABSTRACT}

The Seasat radar altimeter observations of a $100 \mathrm{~km}^{2}$ area in South Greenland are compared to a detailed, ground-based survey, using "geoceivers" and pressure altimeters. The comparison shows the Seasat measurement of distance between satellite and earth to be accurate to the level of the geoceiver determined surface $( \pm 2 \mathrm{~m})$. Due to the great distance between satellite and surface, finer details of surface topography are not revealed in the satellite measurements. As the satellite tends to lock onto hills in the vicinity of the sub-satellite track, the satellite tends to overestimate the true surface elevation. However, a similar altimeter would make a similar overestimate, allowing accurate differential measurement of volume changes between the two surveys.

\section{INTRODUCTION}

Ice surface topography is of considerable interest, since surface height determines ice volumes; change in height with time determines net mass balances; the direction of surface slope is the same as ice-flow direction; surface slope and depth determines total shear, and surface undulation is controlled by bottom topography and the physical properties of ice.

The first satellite-based (Geos-3, 1975) topography measurement (Brooks and others, 1978) was a revolution. Now, it is possible to map the ice surface on a "global" scale, with all coordinates referenced to a common geocentric coordinate system. Although the first estimate of the accuracy $(2 \mathrm{~m})$ was too optimistic, these early results were a significant improvement. As the orbit of Geos-3 just reached $65^{\circ} \mathrm{N}$, only South Greenland was mapped. Seasat, which contained an improved altimeter, was launched in 1978. As the orbit reached $72^{\circ} \mathrm{N}$, the major part of the Greenland Ice Cap was mapped with hitherto unseen precision (Zwally and others 1983; Zwally 1984). The reproducibility of these measurements was demonstrated to be better than $1 \mathrm{~m}$ on a smooth and horizontal ice surface in Central Greenland, near the ice divide. In fact, the reproducibility was close to the height of a sastruga.

It is more difficult to estimate the error on a sloping and undulated surface. First, the satellite is $800 \mathrm{~km}$ above the surface and it emits a relatively wide-angled radar signal. Therefore, the satellite "sees" the point on the surface closest to the satellite and not the point directly below (Thomas and others 1983). This introduces a slope induced error (Brenner and others 1983). Next, the altimeter was designed to measure ocean wave properties. On an ice sheet surface, with faster changes in distance between surface and satellite, the altimeter frequently runs "off scale". Although this error could be corrected for, the actual ice surface may create radar signal returns that, at times, make it difficult to identify the first return signal from the surface (Martin and others 1983). Absolute precision has been estimated from comparison with "geoceiver fixes" (Brooks 1982).

The correction applied to the raw Seasat measurements is here verified on a sloping and undulated surface in South
Greenland. The result is that the reproducibility of the measurements is almost as good as that from the smooth horizontal Central Greenland surface. The absolute level of the distance measurements is correct within the accuracy of the surface; however, the wide footprint of the radar beam prevents details of surface topography from being resolved.

\section{Measurement of the Greenland Ice Sheet surface elevation}

Until recently, only sparse and incompatible measurements of the surface topography of the Greenland Ice Sheet existed. As the survey had to be carried out on the surface, it was associated with high cost, in terms of money, equipment, and labour. Consequently, most surface measurements were made barometrically. Although these measurements are reproducible within a few meters, the absolute height of the surface varies in the order of $100 \mathrm{~m}$. A few, high-precision traverses have been performed, most noticeably along the EGIG track (Malzer 1964; Seckel 1977). Although these measurements are accurate within $3 \mathrm{~m}$, they are restricted to a line, with little spatial coverage. These measurements were, in principle, above mean sea level.

In 1972, the first geoceiver measurement on the Greenland Ice Sheet was made by Mock (1976). In the geoceiver measurement, the location of the observer is determined relative to the US TRANSIT satellites, using the doppler shift of the satellites. A typical measurement takes 4 days, while 40 selected satellite passes are recorded. Later, if the precise satellite emphemeris can be obtained from DMATHC, an accuracy of about $1 \mathrm{~m}$ in latitude and longitude and $2 \mathrm{~m}$ in height can be obtained. These coordinates are defined by a geocentric, global, coordinate system and do not relate to some local system (e.g. mean sea level). The geocentric, coordinate system has its origin in the earth center of mass, $\mathrm{Z}$-axis along the mean rotation axis and $X-Z$ plane through Greenwich. The XYZ coordinates of the observer are frequently converted to latitude, longitude, and height above a reference ellipsoid. In this work, the ellipsoid used is WGS-72 ( $\mathrm{a}=6378135 \mathrm{~m}$, $\mathrm{f}=298.26$ ). The difference between the ellipsoid and mean sea level is the geoid height; thus, if a surface has been measured both by levelling and geoceiver fixes, the difference between these two sets of measurements is the geoid height.

If the precise satellite ephemeris is not available, one or more receivers, operating simultaneously at a fixed position, may serve as references. If the distance between the receivers is not too great - some hundred kilometers - the accuracy will be better than the one obtained from the position calculated from the precise ephemeris. The parameter measured, however, is not the geodetic position of the observer, but the distance to the reference position.

\section{Seasat measurements}

The Seasat satellite measured the ice-surface elevation, using a radar sounder. Before the sounder readings can be interpreted in terms of surface elevation, a number of corrections and considerations must be applied: 
1. Orbit height. As the altimeter measures the distance from satellite to the ice surface, the satellite orbit must be known, in order to calculate surface elevation.

2. Surface slope. In the case of a sloping plane, the surface directly below the satellite is $8 \mathrm{H}=0.5 \times \mathrm{H \alpha}^{2}$ below the surface determined by the satellite altimeter (Brenner and others 1983). $\mathrm{H}$ is the satellite altitude $(800 \mathrm{~km})$ and $\alpha$ the surface slope in radians.

3. Along-track averaging. The return signal waveform is the average of 100 samples over a $662 \mathrm{~m}$ distance, thus the along-track resolution is $662 \mathrm{~m}$.

4. Waveform retracking. The return pulse shape over an ice sheet is significantly more complicated than that over the ocean. The reason is that several points on the ice may have the same distance to the satellite. As a result, the distance measuring equipment (tracker) in the satellite may not be able to follow the surface. As long as the tracker is locked onto the surface echo, this error can be corrected for by fitting a single or double ramp waveform to the return pulse shape (Martin and others 1983). The resultant range error is estimated to the decimeter level.

5. Surface penetration. Cold firn allows the radar signal to penetrate the snow. As a result, a radar return may be obtained not just from the air-firn transition, but also from features below the surface, e.g. melt layers. The retracking algorithm used should reduce the risk of following a wrong surface.

6. Atmospheric pressure. The atmosphere introduces a delay of the radar signal corresponding to a few meters. Using a correction depending on surface elevation, the error may be reduced to around $10 \mathrm{~cm}$.

7. Geoid and solid earth tide. The satellite orbit is known in a coordinate system, with origin in the earth center of mass. If surface elevation is wanted above mean sea level, the geoid must be known. The estimated error of the geoid is around $2 \mathrm{~m}$ on the ice cap.

The resulting accuracy of the Seasat surface is difficult to estimate, even when excluding geoid errors, as this is not really an error, but a question of the coordinate system used. Under favourable circumstances, the noise of the range measurement itself is $25 \mathrm{~cm}$ and orbit errors $1.6 \mathrm{~m}$
(Zwally and others 1983). On a normal ice cap, with slopes and undulations, the error due to these surface irregularities will completely dominate the other errors, even after correcting for mean surface slope.

\section{Surface measurement near Dye-3}

August 1981 was the end of the 3 year Greenland Ice Sheet Program (GISP) deep drilling, which resulted in recovery of a $2037.6 \mathrm{~m}$ deep ice core (Dansgaard and others 1982). The drilling took place in South Greenland, $600 \mathrm{~m}$ from the Dye-3 radar station $\left(65^{\circ} \mathrm{N}, 44^{\circ} \mathrm{W}, \mathrm{h}=2480 \mathrm{~m}\right)$, The Dye-3 position was selected for logistic reasons; glaciologically, it was not considered the most favourable site. The accumulation is relatively high $(55 \mathrm{~cm}$ of ice equivalent per year). Occasional summer melting changes ice properties and the site receives a complicated precipitation pattern from both sides of the ice divide, located $30 \mathrm{~km}$ to the West. Furthermore, the glacier is here resting on a mountainous bed (Overgaard and Gundestrup 1985), which complicates the ice flow. In order to correct the information from the deep core for local effects, a program has been initiated upstream of Dye-3. This includes a number of ice cores ( $5 \mathrm{~m}$ to $175 \mathrm{~m}$ deep), temperature profiles, ice surface velocities, ice thickness, and surface topography. The reasons for measuring surface topography are that surface slope is the "driving force" for ice flow and that undulation creates changes in accumulation and temperature. Undulations are caused by subglacial mountains. They are consequently indications of complicated ice flow and the magnitude of the undulations is indicative of ice properties in the deeper strata (Dahl-Jensen 1985; Gundestrup and Hansen 1984). Ice thickness and surface topography are of primary interest, whereas the absolute level of the surface is of minor importance for this work. Consequently, the survey was performed barometrically using a reference barometer at a nearby fixed position to correct for barometric pressure changes. The absolute level of the surface is adjusted to several geoceiver fixes in the area. Thus the resulting surface (Figure 1) is in the coordinate system used by the satellites.

In Figure 1, all surface elevation measurements are

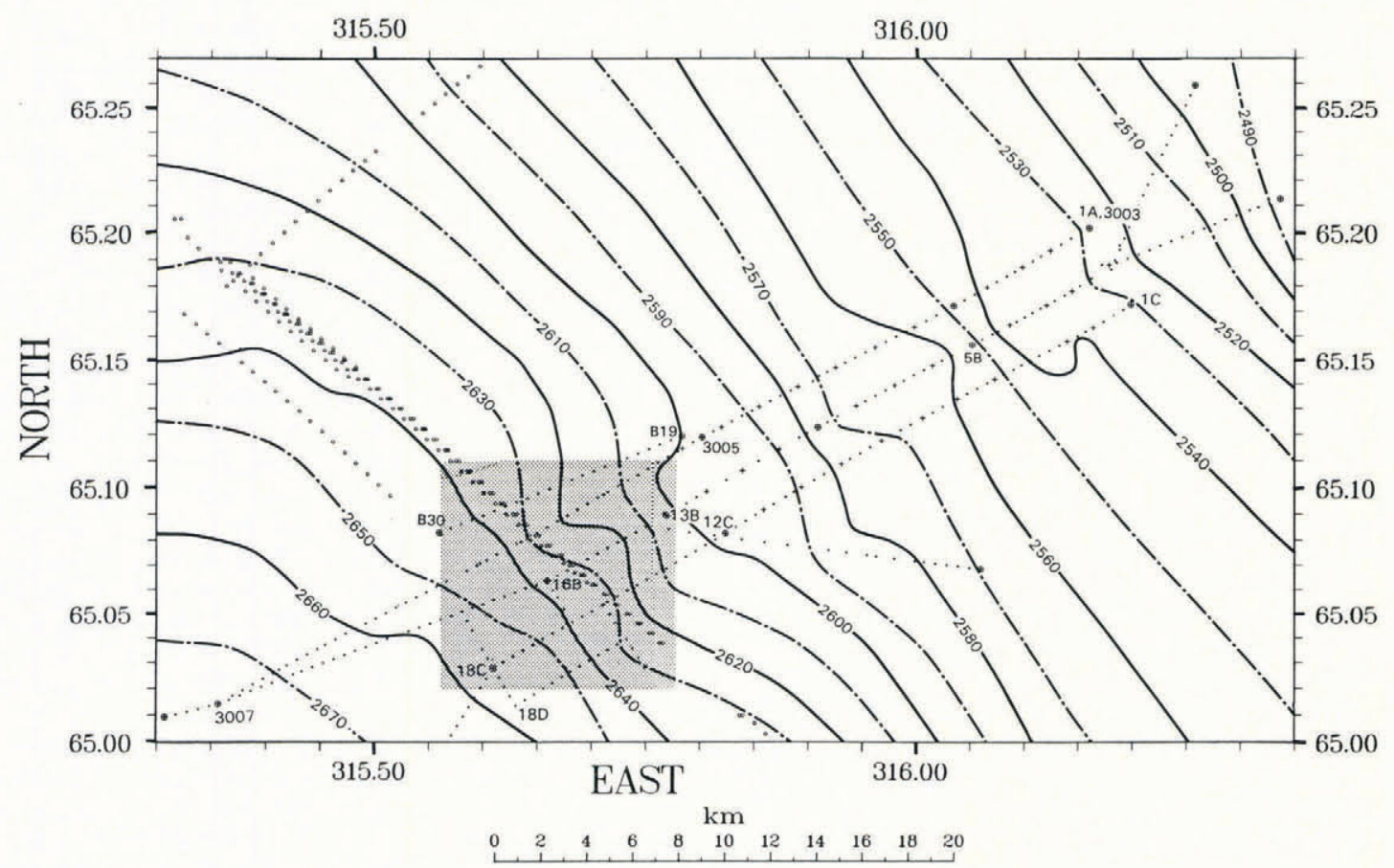

Fig.1. Surface elevation near Dye-3. Elevation is with respect to the WGS-72 ellipsoid. The elevation above mean sea level is about $40 \mathrm{~m}$ less than the indicated elevation. Barometrically measured points are marked with a small dot, geoceiver points with a $\otimes$. Seasat subtrack points are marked with a small open circle. The shaded area is expended in Figure 2. The map is computed from geoceiver, barometer and Seasat data. The naming of the points is in agreement with that used in the OSU strainnet. 3003, 3005 and 3007 are geoceiver points from that network. The deep drill site is midway between $1 \mathrm{~A}$ and $\mathrm{IC}$. The ice-divide is located north-south just east of 3007 . 
marked with a small dot, and geoceiver fixes with a $\otimes$. The Seasat crossings in the western part of the map are marked with an open circle. The maps are based on a computer-generated color map (Uniras), using a pixel size of $400 \times 400 \mathrm{~m}$ and some degree of smoothing. Input data are barometric measurements, geoceiver fixes and Seasat elevation measurement. Close to point $16 \mathrm{~B}, 3$ Seasat tracks cross 5 lines of surface measurements. This area is expanded in Figure 2. Again, this map is based on a "Uniras" map, using smoothing and a pixel size of $250 \times 250 \mathrm{~m}$. The input data are barometric measurements and 3 geoceiver fixes, mainly following the OSU strain-net (Whillans and others 1984). In addition to the general surface slope, which runs south-west to north-east, several undulations with an amplitude of $20 \mathrm{~m}$ and a wavelength of $5 \mathrm{~km}$ can be seen. The surface topography resembles McIntyre and Drewry (1984) type 2, but with a smaller wavelength. The surface is compared with the Seasat range measurement.

\section{How accurate?}

The barometers used are Thomsen type 3B4. They have a reproducibility of $1 \mathrm{~m}$. The accuracy of the geoceiver has been checked close to Dye-3 at a fixed point. This station was remeasured in 1972, 1980,1981 and 1983 (Reeh and Gundestrup 1985). The result is that latitude and longtitude have a standard deviation of $0.7 \mathrm{~m}$; height $1.6 \mathrm{~m}$. These figures have been verified by re-measuring station $16 \mathrm{~B}$ in 1981, 1983 and 1984. The error in altitude is higher than in longitude and latitude because residual, ionospheric effects create a bias in altitude.

In summary, the standard error of the surface in Figure 2 can be estimated as $2 \mathrm{~m}$.

\section{Comparison with Seasat}

Three Seasat tracks pass Figure 2, revolutions 1193, 1236 and 1279. In Figure 3, the non-slope-corrected Seasat altitude is compared with the sub-satellite surface, measured barometrically and by geoceiver. Although the satellite shows good reproducibility $(1.6 \mathrm{~m})$, errors as high as $20 \mathrm{~m}$ are noted. Part of this error can be removed by a suitable slope correction, but the finer details of the surface are lost.

The surface topography (Figure 2) is used to calculate the point on the surface closest to Seasat and the distance from Seasat to this point. The distance is then converted to an apparent surface elevation, i.e. the surface elevation that Seasat should have measured over this surface. Figure 4 shows this elevation compared with the actual measured surface and the real ice surface, for revolution 1236. The calculated and the observed elevation compares favourably, for the 3 passes, the difference being $1.6 \mathrm{~m} \pm 2.5 \mathrm{~m}$ compared with $11 \mathrm{~m} \pm 4.7 \mathrm{~m}$ between measured and actual surface. The difference of $1.6 \pm 2.5 \mathrm{~m}$ is in agreement with the $1.6 \mathrm{~m}$ accuracy over an ideal horizontal surface, the accuracy of the range measurement with corrections being slightly degraded.

On Figure 2, lines are drawn from the Seasat subsatellite point to the point closest to the satellite. The Seasat beam locks onto hills on the surface and the area between hills is not measured. A similar effect, on a larger scale, has been observed on ice shelf edges (Thomas and others 1984).

\section{CONCLUSION}

1. Techniques for retracking radar altimeter data, as described in Martin and others (1983) and for correcting

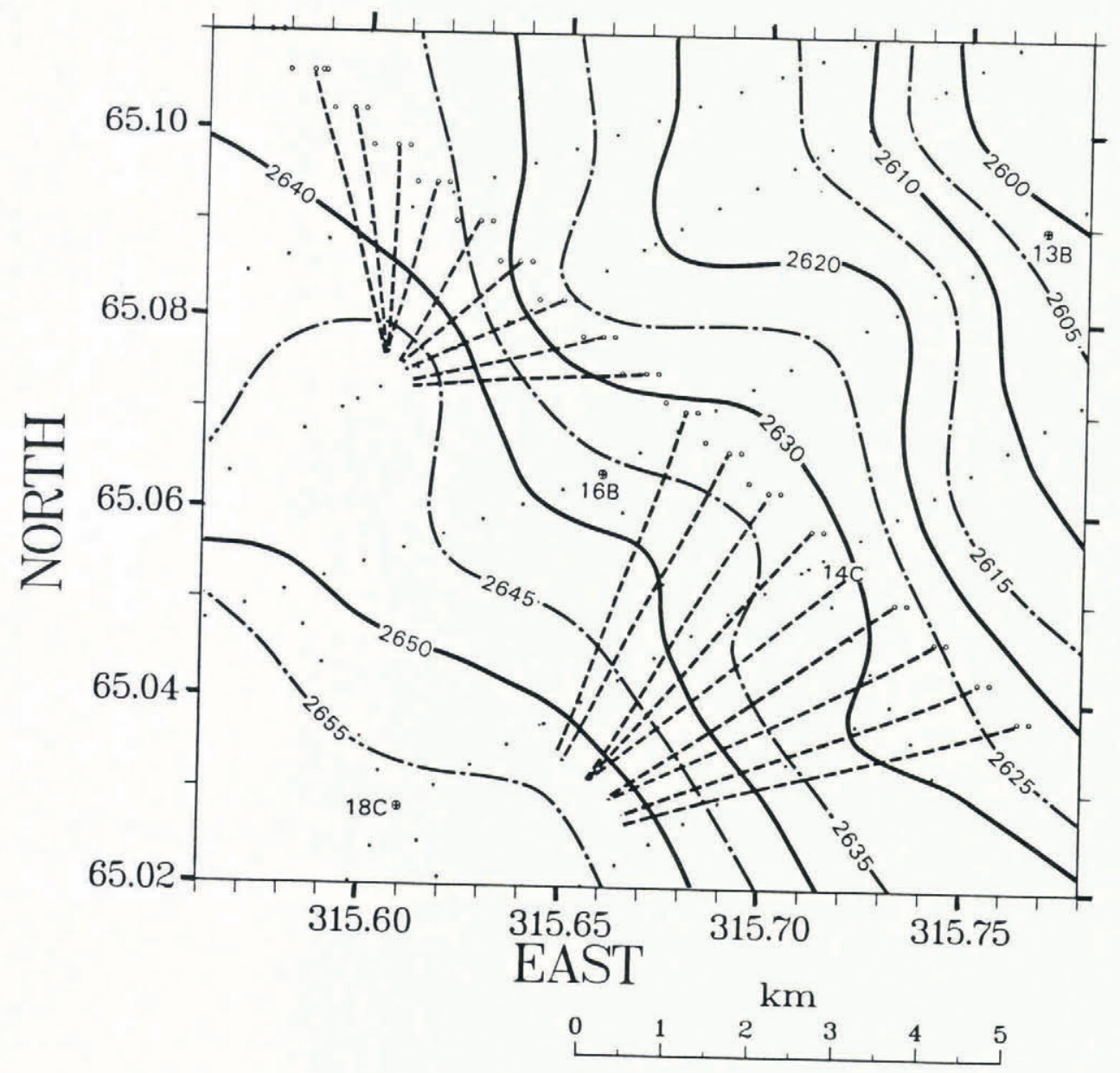

Fig.2. Surface elevation near 16B. Symbols as in Figure 1. The map is computed from geoceiver and barometer measurements. 3 Seasat passes cross the map south-east to north-west. Revolution 1193 is to the west. 1236 center and 1279 to the west. For Seasat revolution 1236 the distance between the sub-track point and the point on surface closest to the satellite is marked with a dashed line for each sample. 


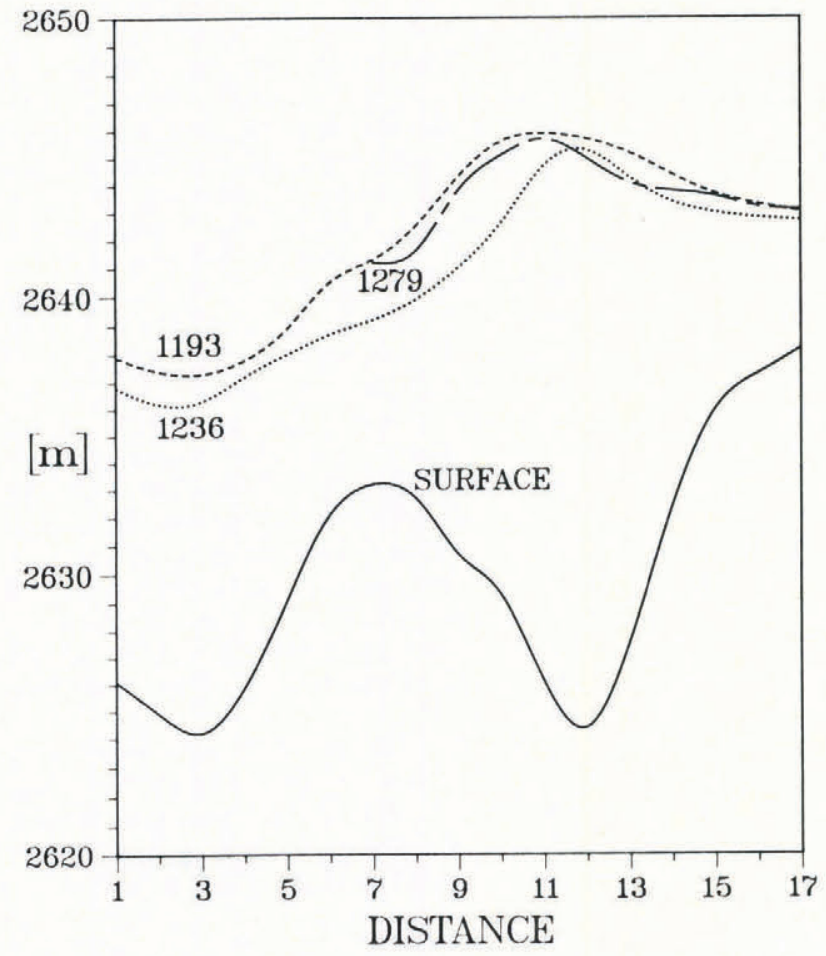

Fig.3. Seasat elevation for revolutions 1193, 1236 and 1279, and actual sub-track surface height from Figure 2 versus distance. The unit on the abscissa is the sample number. The distance between the markings is $662 \mathrm{~m}$.

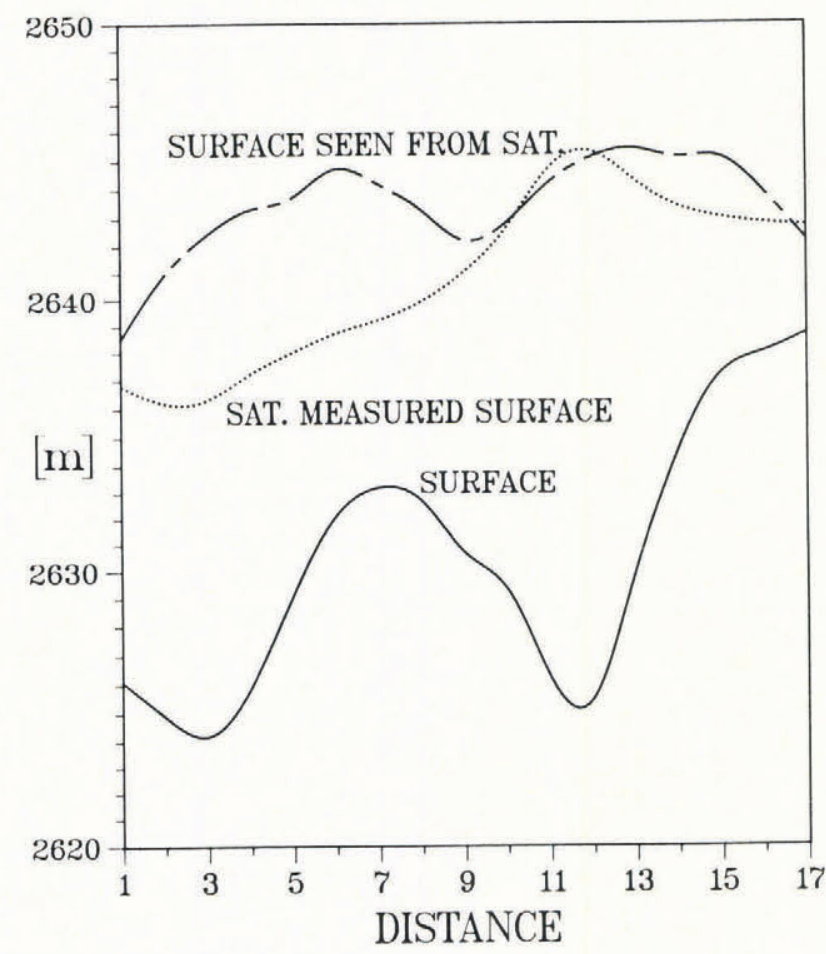

Fig.4. True sub-track surface elevation as measured by barometer and geoceiver, Seasat-measured elevation, and the elevation Seasat should have measured over the surface in Figure 2 for revolution 1236.

for slope-induced errors, as described in Brenner and others (1983), are verified by 3-dimensional surface measurement of topography.

2. The altimeter tends to lock on to hills or rises in the vicinity of the sub-satellite track and to jump from one hill to another. The terrain between the hills cannot be resolved.

3. Although the elevations overestimate the true surface elevation, a similar altimeter would make a similar overestimate, allowing an accurate differential measurement of volume change between the two surveys (Griffiths 1984).

4. Even on a sloping and undulating surface, the Seasat range measurement is accurate to the level of the geoceiver determined surface $(2 \mathrm{~m})$.

\section{REFERENCES}

Brenner A C, Bindschadler R A, Thomas R H, Zwally H J 1983 Slope-induced errors in radar altimetry over continental ice sheets. Journal of Geophysical Research 88 (C3): 1617-1623

Brooks R L 1982 Satellite altimeter results over East Antarctica. Annals of Glaciology 3: 32-35

Brooks R L, Campbell W J, Ramseier R O, Stanley H R, Zwally H J 1978 Ice sheet topography by satellite altimetry. Nature 274(5671): 539-543

Dahl-Jensen D 1985 Determination of the flow properties at Dye 3, south Greenland, by bore-hole-tilting measurements and perturbation modelling. Journal of Glaciology 31 (108): $92-98$

Dansgaard W and 6 others 1982 A new Greenland deep ice core. Science 218(4579): 1273-1277

Griffiths H D 1984 Special difficulties of retrieving surface elevation over continental ice. In Guyenne T D, Hunt J J (eds) ERS-1 radar altimeter data products; proceedings of an ESA workshop held in Frascati, Italy on 8-11 May, 1984. Noordwijk, ESTEC: $61-65$ (ESA SP-221)

Gundestrup N S, Hansen B L 1984 Bore-hole survey at Dye 3, south Greenland. Journal of Glaciology 30(106): $282-288$

McIntyre N F, Drewry D J 1984 Modelling ice-sheet surfaces for ERS-1's radar altimeter. ESA Journal 8(3): $261-274$

Mälzer H 1964 Nivellement über das grönländische Inlandeis. Meddelelser om Gronland 173(7)

Martin T V, Zwally H J, Brenner A C, Bindschadler R A 1983 Analysis and retracking of continental ice sheet radar altimeter waveforms. Journal of Geophysical Research 88(C3): 1608-1616

Mock S J 1976 Geodetic positions of bore-hole sites of the Greenland Ice Sheet Program. CRREL Report 76-41

Overgaard S, Gundestrup N S 1985 Bedrock topography of the Greenland ice sheet in the Dye 3 area. In Langway $\mathrm{C} \mathrm{C} \mathrm{Jr}$, Oeschger H, Dansgaard W (eds) Greenland ice core: geophysics, geochemistry, and the environment. Washington, DC, American Geophysical Union: 49-56 (Geophysical Monograph 33)

Reeh N, Gundestrup N S 1985 Mass balance of the Greenland ice sheet at Dye 3. Journal of Glaciology 31(108): 198-200

Seckel H 1977 Höhenänderungen im grönländischen Inlandeis zwischen 1959 und 1968. Meddelelser om Gronland 187(4)

Thomas R H, Martin T V, Zwally H J 1983 Mapping ice-sheet margins from radar altimetry data. Annals of Glaciology 4: 283-288

Whillans I M, Jezek K C, Drew A R, Gundestrup N 1984 Ice flow leading to the deep core hole at Dye 3, Greenland. Annals of Glaciology 5: 185-190

Zwally H J 1984 Observing polar-ice variability. Annals of Glaciology 5: 191-198

Zwally $\mathrm{H}$ J, Bindschadler R A, Brenner A C, Martin T V, Thomas R H 1983 Surface elevation contours of Greenland and Antarctic ice sheets. Journal of Geophysical Research 88 (C3): 1589-1596 